\title{
The online student experience: A MAC-ICE thematic structure
}

\author{
Mel Henry \\ Curtin University
}

\begin{abstract}
Attracting and retaining students in a COVID-distanced online higher education market is more important than ever. With limited access to campus, extensive student choice, and precarious institutional revenue, understanding what makes a positive online student experience in the eyes of students themselves, is vital for institutional survival. Through an in-depth case study of online first-year university students, this research identified six themes that describe students' lived experiences of online education $(\mathrm{OE})$, summarised as a motivation, ability, circumstances - interaction, curriculum, environment, or MAC-ICE, thematic structure of the online student experience (OSE). Where online students are deeply motivated, possess the skills to participate effectively in online university education, and are situated in conducive circumstances, they may be well placed for a positive student experience. Supplementing this, universities may facilitate a quality OSE through meaningful interaction with instructors, peers, and course content; flexible, challenging, and relevant curricula; and a reliable, innovative learning environment commensurate with the on-campus student experience. The rich description provided by this research enables generation of propositions about students' experiences of $\mathrm{OE}$, and suggests opportunities to enhance the OSE through consideration of identified themes.
\end{abstract}

Implications for practice or policy:

- The OSE can be described by students' motivation, ability, and circumstances, alongside institutional interaction, curriculum, and environment.

- $\quad$ OE may be perceived to involve more work, greater concentration, better time management, more self-regulation, and a heavier reliance on technology, than oncampus education.

- OE research may be confounded, where particular MAC-ICE themes are insufficiently considered.

- Online student outcomes may be increased through purposeful consideration of all MAC-ICE themes.

Keywords: online, retention, motivation, skills, interaction, learning design, qualitative

\section{Introduction}

In an online, COVID-distanced world, proximity to campus may no longer drive student choice. A global online higher education (HE) market means students can choose from institutions worldwide, with little benefit gained from residing close to campus. Concurrently, challenges posed by COVID-19 have led to significant drops in university enrolments (Borrello, 2020), placing even greater importance on retaining current students, while continuing to attract students with global choices. Amidst growing student choice and precarious institutional revenue, reputation, quality, and value for money are more critical to institutional survival than ever before. Understanding what makes an effective and valuable student experience, in the eyes of students themselves, therefore, is vital.

While online education (OE) is not new, COVID-19 has brought it to the fore of university operations. Recent distancing measures have seen the vast majority of HE programs move online. OE can no longer be viewed as nice to have. It's core business, essential for the survival of HE. OE, however, has long been criticised for poor student outcomes (Bawa, 2016). Efforts to address these concerns and enhance OE to date have focused on the institution and its teaching, prioritising the development and evaluation of specific strategies to engage learners in online content (Quality Indicators for Learning and Teaching, 2020), neglecting a more holistic and student-centred understanding of the online student experience (OSE). A wealth of valuable teaching and learning resources, for instance, have been shared in response to COVID19, presenting opportunities to enhance the academic experience, while few have shared strategies to support broader online student retention and satisfaction. There exists, therefore, a need to investigate how 
teaching and learning strategies might combine with other student engagement initiatives and experiences beyond the classroom, to appreciate how students experience OE in its entirety.

Despite a plethora of evaluation research and best-practice guidelines, concerns continue to be raised about OE outcomes (Stone, 2017). Recent moves to widespread OE have also seen a rise in student dissatisfaction and calls for fee discounts (Chrysanthos, 2020), signalling students' perception of poor quality OE. A great deal of research has examined online student outcomes, nonetheless, and evidence suggests quality OE is possible.

Historically, OE literature has largely focused on comparing discrete online and on-campus student outcomes. Several studies have demonstrated poor learning, satisfaction, and retention of online students, compared to their on-campus peers (Garratt-Reed et al., 2016; Xu \& Jaggars, 2014). There also appears widespread belief amongst university staff that online courses are associated with poorer outcomes (Allen \& Seaman, 2014). In contrast, some studies have reported similar learning, satisfaction, and retention outcomes for students in online and on-campus courses (Chen et al., 2017; Driscoll et al., 2012), and a small number have shown stronger outcomes for OE, particularly where courses have been explicitly designed for online delivery (Lo et al., 2011). Regardless of stakeholder perceptions, the literature suggests OE can deliver strong outcomes, where programs are purposefully designed to meet the needs of online students.

Prior OE research and practice is largely grounded in the understanding of education as it happens on campus, with little consideration of potential differences (Bawa, 2016). To effectively compare the oncampus and OSE, one must be confident they are otherwise comparing like with like. Student characteristics, in particular, can differ substantially between on-campus and OE (Wieser et al., 2017), as would aspects of curriculum design and delivery. The literature rarely offers sufficient information to effectively discern the underlying design of compared programs and associated conditions, however, to determine whether respective on-campus and OSEs were, in every sense, equivalent, or to account for potentially confounding variables (e.g., Wynegar, \& Fenster, 2009). With insufficient information to determine which elements of the student experience might have differed, it is difficult to conclude what might have contributed to poorer outcomes in OE.

With potential differences between on-campus and OE concealed, assumed determinants of online student outcomes are seemingly extrapolated from understanding of on-campus education (e.g., Cavanaugh \& Jacquemin, 2015; Wynegar \& Fenster, 2009), and online courses adapted from campus-based programs (Moore \& Greenland, 2017). OE research and associated conceptualisations of quality have also relied heavily on quantitative measures or surveys investigating predefined variables relevant to on-campus education, and on comparing online and on-campus students' grades (e.g., Garratt-Reed et al., 2016; Su \& Waugh, 2018). As a result, understanding of the OSE remains limited to conceptualisation of traditional HE.

While universities have long recognised the importance of the total student experience (Benckendorff et al., 2009), OE research and practice remain focused largely on academic perspectives of student engagement with learning and teaching. Aspects of the broader student experience, such as lifestyle, extracurricular activities, support, and guidance, along with the student perspective, are rarely considered in the evaluation of OE (e.g., Cavanaugh \& Jacquemin, 2015), with few studies examining the broader experience of being an online student. We have, nonetheless, seen an emergence of valuable qualitative, student-centred OE research in recent years (e.g., Stone \& O'Shea, 2019); yet such studies have tended to focus intensely on the student, equally overlooking a more holistic view of the total OSE. As such, a dichotomy of evidence has transpired, with quantitative evidence of academic outcomes, in parallel to qualitative description of students' personal circumstances and challenges, presenting a disjointed and piecemeal picture of the total OSE. While online teaching strategies and personal challenges are important components of the OSE, a holistic, student-centred perspective, which brings together and adds to these understandings, is essential to appreciate the wider context for OE, and to interpret online student outcomes.

With limited student voice, and reliance on predefined constructs, grounded in traditional HE, understanding of the OSE is restricted to known issues. Potentially critical aspects may be overlooked and a deeper understanding of the online student perspective inhibited. An open exploration of students' holistic experiences of $\mathrm{OE}$, described by students themselves, therefore, is an essential precursor for universities to ensure a quality OSE in the eyes of their students. 


\section{Methodology}

\section{Research aim}

This research involved an in-depth case study of online students. It sought to describe how students construct their lived experiences of $\mathrm{OE}$, and attribute meaning to these experiences, in the context of their first year of study at an Australian public university. It is acknowledged that data was collected prior to the COVID-19 outbreak, and as such, reflects experiences of online students pre-COVID.

The research was conducted within an interpretivist, critical-realist philosophy, seeking to understand the phenomenon of the OSE, as it was experienced by first year university students (Findlay et al., 2006). A descriptive phenomenological approach was adopted, considering multiple meanings within a sociocultural context, while actively separating the researcher's subjective interpretations, building a detailed explanation of what participants experienced as OE (Kleiman, 2004).

\section{Participants}

The case university has a large and diverse offering of online courses, primarily delivered through Blackboard, with specific pedagogical guidelines governing OE. A range of supplementary support is available to online students, including web-based materials and specialist services, accessible via email and/or telephone.

Following approval from the university's human research ethics committee, 43 first-year domestic students were recruited through the university's online student portal, and via online course coordinators. Participants were provided with a detailed information statement and consent form prior to interview, and entered in a prize draw for a \$500 AUD gift voucher following participation. Participants included students in online bachelor degree, graduate certificate, and graduate diploma courses, in which they were required to engage with instructors and course materials via the internet, with no expectation of attending a university campus. Table 1 summarises participants' self-reported characteristics and enrolment information. The sample included greater proportions of female, bachelor degree, part-time, and mature aged (aged 21 years or older) students, reflecting the university's online student population. While many participants had some experience of university study (in a different field), the majority were studying online for the first time, and described themselves as reasonably proficient with technology. Additional sample demographics, such as first-in-family or socio-economic status, were not explicitly collected, though it is noted these would offer a valuable lens through which to investigate the OSE for a larger sample. 
Table 1

Participant profile

\begin{tabular}{|c|c|}
\hline Characteristic & $\begin{array}{c}\text { Number (percentage) } \\
\text { of participants }\end{array}$ \\
\hline \multicolumn{2}{|l|}{ Gender } \\
\hline - $\quad$ Male & $14(33 \%)$ \\
\hline - Female & $29(67 \%)$ \\
\hline \multicolumn{2}{|l|}{ Age } \\
\hline - School leaver & $1(2 \%)$ \\
\hline - $\quad 21$ years or older & $40(93 \%)$ \\
\hline - $\quad$ Non-disclosed & $2(5 \%)$ \\
\hline \multicolumn{2}{|l|}{ Technical experience (self-reported) } \\
\hline - Highly experienced with technology and OE & $7(16 \%)$ \\
\hline - Experienced with technology, with some OE & $10(23 \%)$ \\
\hline - $\quad$ Proficient with technology & $23(53 \%)$ \\
\hline - $\quad$ Borderline proficient with technology & $2(5 \%)$ \\
\hline - $\quad$ Inexperienced with technology & $1(2 \%)$ \\
\hline \multicolumn{2}{|l|}{ Study load } \\
\hline - Full-time (enrolled in at least three units/semester) & $18(42 \%)$ \\
\hline - $\quad$ Part-time (enrolled in less than less than three units/semester) & $25(58 \%)$ \\
\hline \multicolumn{2}{|l|}{ Course level } \\
\hline - $\quad$ Bachelor degree & $33(77 \%)$ \\
\hline - $\quad$ Graduate certificate & $6(14 \%)$ \\
\hline - $\quad$ Graduate diploma & $4(9 \%)$ \\
\hline \multicolumn{2}{|l|}{ Field of study (majors) } \\
\hline - $\quad$ Health (psychology, social sciences, social work, nursing, public health) & $23(53 \%)$ \\
\hline - $\quad$ Business (management, human resources, occupational health and safety) & $13(30 \%)$ \\
\hline - Law & $3(7 \%)$ \\
\hline - Technology (computer science, security, technology) & $4(9 \%)$ \\
\hline - $\quad$ Other (planning, writing) & $2(5 \%)$ \\
\hline
\end{tabular}

Note. Technical experience ratings were self-reported and considered both computer literacy and OE experience. Some participants were enrolled in more than one field of study.

\section{Data collection}

In-depth, synchronous, text-based interviews were conducted and automatically transcribed through Blackboard and Adobe Connect chat tools, upon enrolment and again after one and two semesters of study. Second and third interviews were only conducted with participants who had completed preceding interviews. An interview schedule was used for each time point, with a similar list of exploratory questions designed to prompt participants to discuss broad elements of their experiences openly.

The interview schedules reflected a range of potential OSE elements, identified in prior OE and student experience research. Specifically, participants were invited to openly discuss their: attendance and participation; course delivery; assessments; interaction with others; technology; time and place of learning engagement; challenges; and support needs. Effort was taken to ensure the discussion was not limited to these topics, however, and the researcher simply used the pre-defined questions as prompts to encourage participants to expand on their lived experiences.

\section{Data analysis}

Participants' responses were explored and described through a process of thematic analysis, in line with descriptive phenomenology. Each transcript was closely reviewed and individual meaning units (Karlsson, 1993), signifying discrete ideas or concepts, identified and assigned a code (Braun \& Clarke, 2006; Kleiman, 2004). Once transcripts were coded, meaning units were sorted, refined and grouped into themes and sub-themes (Braun \& Clarke, 2006; Karlsson, 1993). Each theme represented an important aspect of the OSE, reflecting a pattern of meaning across the participant sample, across the three time points, and/or across the data set (Braun \& Clarke, 2006); as well as the depth of discussion and/or explicit significance ascribed by participants. The intention was to build a holistic and qualitative description of the OSE, in 
which any emerging theme was viewed as valid, regardless of statistical prevalence. A rich thematic description of the data was then prepared (Braun \& Clarke, 2006), and a conformability audit conducted (Guba \& Lincoln, 1982), returning to raw data extracts to validate the analysis (Braun \& Clarke, 2006; Chamberlain, 2009; Kleiman, 2004). Throughout data collection, the researcher also made notes about her subjective interpretations and thoughts arising while conducting the interviews, in order to separate out, or bracket, these from the interview data and prevent biased interpretation (Karlsson, 1993).

\section{Findings}

Six themes were identified that described participants' lived experiences of OE, broadly separated into learner and institutional factors. Learner themes described students' individual capacity to engage with OE: their motivation, ability, and circumstances. Supplementing these, three institutional themes described aspects of the OSE related to the university: interaction, curriculum, and environment. Together, these themes were summarised as a: motivation, ability, circumstances - interaction, curriculum, environment (MAC-ICE) thematic structure of the OSE, visualised in Figure 1. Participants' experiences associated with each theme are described below, with quotes provided to illustrate the participant voice, using pseudonyms.
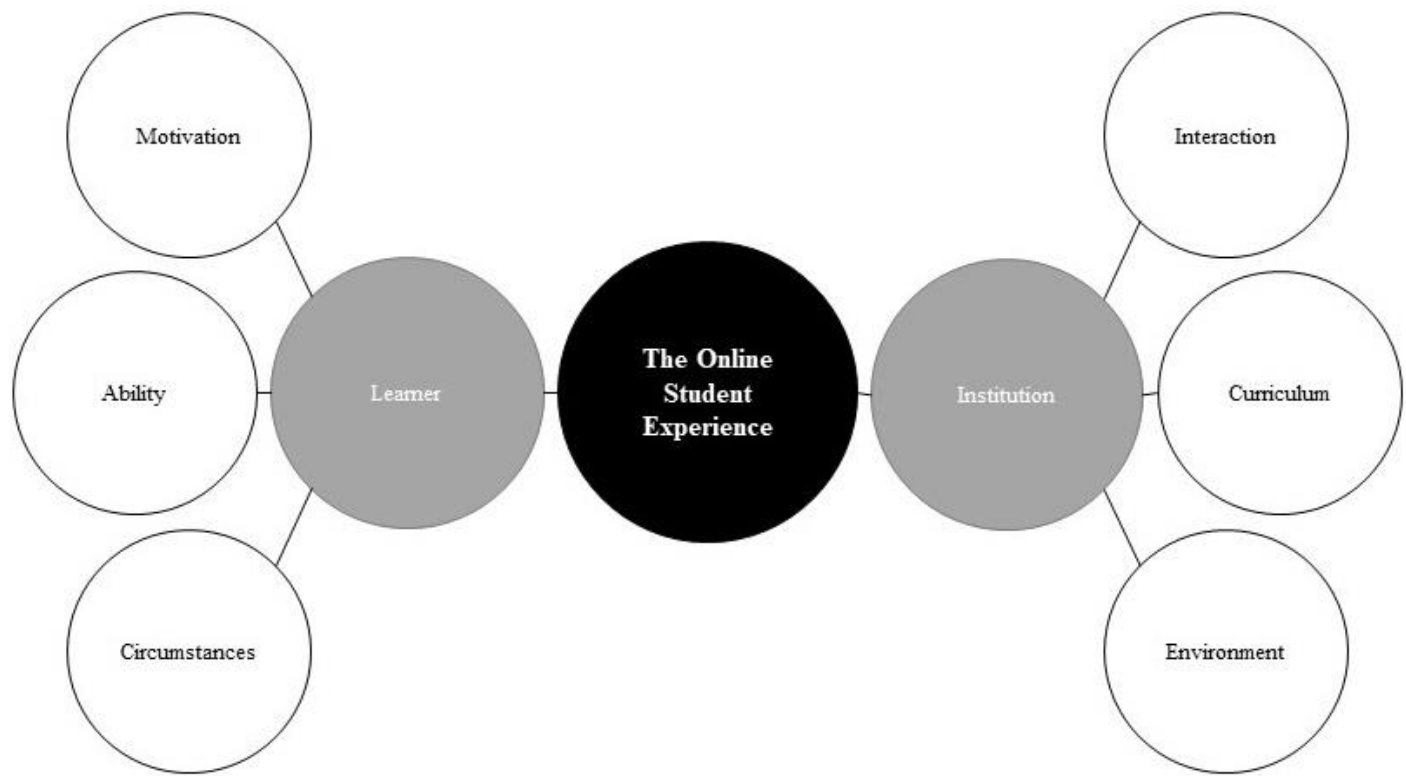

Figure 1. Identified learner (MAC) and institutional (ICE) themes, summarised as a MAC-ICE thematic structure of the OSE

\section{Motivation}

The motivation theme described participants' intrinsic desire to approach and sustain participation in their learning, reflecting their concentration, self-efficacy, interest and passion, commitment, and experiences of rewards. Many participants found it difficult to concentrate on their studies, manage distractions and avoid procrastination. Some acknowledged this was a normal challenge of university, but they needed to be more disciplined in the absence of visual cues, strict course scheduling, and face-to-face interaction, which they felt might have motivated them further had they been studying on campus. John, for instance, felt tempted to procrastinate during his first semester, saying: “... I found myself thinking there is so much other work/things to be done around the house etc."

Participants were mostly confident in their capacity to succeed. Though many found their studies challenging, feedback and encouragement from instructors and having overcome difficulties, reassured students they were capable. Following her second semester, for instance, Julie described her growing selfefficacy, adding: "I think that I am feeling more at ease and more confident im [sic] my abilities now. Where as in the beginning I was a bit doubtful of my abilities." 
Participants mostly found their studies interesting and cherished the opportunity to extend their knowledge. Some acknowledged that their interest sometimes waned, and they needed additional ways to motivate themselves during more challenging or mundane parts of their course. Aidan, for instance, said in his first semester: "I'm sure the excitment [sic] will drain as I dive deeper into the course but for now its [sic] all rather enjoyable!"

Participants' self-described commitment to their studies fluctuated across their first year. Many struggled to remain consistently invested once their initial excitement waned and their course became more difficult. Lisa, for instance, described her commitment as the most challenging aspect of her first year, adding: "It's not difficult. It's just commitment really."

Participants also spoke of personal, intellectual, social, and professional rewards experienced as a result of their studies, having been offered jobs, applied learning in concurrent employment, and/or felt more confident doing particular tasks at work. Participants felt proud of what they had achieved, and some had inspired significant others to also consider university. The acquisition of new knowledge was itself felt to be particularly rewarding and transformative. As Julie described, following her second semester: "I have grown within, I have learnt a lot, I have become more focused and have become more motivated as a person. My family comment on the changes."

\section{Ability}

The ability theme described participants' self-assessed skills, knowledge and experience utilised and developed during their course, including academic skills, content knowledge, computer literacy, organisation and time management, and self-regulation. Many participants struggled to adapt to university learning. They found it difficult to understand and meet expected academic standards, particularly regarding referencing, critical thinking, information literacy, and academic language. Less academically experienced students described feeling at a disadvantage, overwhelmed, and stressed by the effort to learn and apply new skills, on top of participating in the course itself. They expected their skills would continue to develop, nonetheless, and this learning curve would begin to slow, enabling them to engage more efficiently in learning activities. As Valentina described, in her second semester: "I think you get a little more understanding of what is expected of you each semester ... I think you grow as you go."

Several participants felt underprepared for the heavy reliance on technology, having not anticipated using particular systems/software, such as social media. Students with limited technical experience found this generated a very steep learning curve, affecting their capacity to keep up with study. Justin, for instance, described his shock at realising technical weaknesses during his first semester, adding: "To put it mildly BLODDY [sic] HARD ... I did find the course if you were computer literate, ok, but I wasn't."

Where participants lacked deep familiarity with applicable content, particularly mathematics, they found this especially challenging. Participants found it easier to relate and understand topics they had prior exposure to through personal experience, prior study, or employment, though this advantage diminished over time. Prior content knowledge allowed many students to focus on more challenging aspects of their experience. Zander, for instance, described during his first semester: "It helps a lot that I'm very experienced in my field."

Many participants found their course to be more self-regulated than expected, with highly flexible units, requiring students to manage their own participation. Some participants valued this flexibility to focus on relevant or interesting aspects, however, many felt neglected by the university, and were concerned they may be off-track or miss important information in the absence of structured engagement. During her first semester, for instance, Catherine described: "I think I was quite overwhelmed to begin with trying to work everything out on my own, and feeling worried that I had missed something important."

With substantial responsibility for regulating their learning, many participants struggled to manage their time well and plan around external commitments and assignment deadlines. Some found their workload overwhelming, became stressed and fell behind, finding it difficult to make up for lost time, regardless of assessment extensions. Many described having underestimated the time required for their study, such as Alana, who added (after two semesters): "Not realistic at all! I totally underestimated the time I would need to devote to study." 


\section{Circumstances}

Participants discussed their personal circumstances, with regard to the many demands on their time alongside study, as well as support available beyond their course, their health and wellbeing, and their physical study environment. Participants described having many priorities besides study, including fulltime work, caring for young children or family with disability, social activities, and exercise. Many struggled to manage these commitments, particularly alongside scheduled learning activities, and found it difficult to find time for study around employment. Participants regularly prioritised family and caring responsibilities over study, adjusting and postponing study to focus on caring, which led them to fall behind or to study at less optimal times. Some felt guilty where they were unable to spend as much time with family as desired, and described their studies having impacted important relationships. They felt stressed, overwhelmed, and inept, and worried their lifestyle had suffered because of their decision to study. As Brenda described, following her first semester: "I feel guilty if I study too much and the impact that has on my family and I feel guilty if I don't study and the impact that has on my grade."

The majority of participants did not seek assistance from university support services, except where they experienced significant difficulties. Participants were largely unsure which services were available to online students, instead relying heavily on family, friends, and employers for support. This support was instrumental in enabling many participants to persist and manage their workload effectively. Participants found it helpful to discuss their studies with others who had studied at university, or were experienced with technology and/or in relevant fields, and valued flexibility and financial support offered by employers. Justin, for instance, found his partner's support integral to completing his first semester, adding: "I also got my wife to type assignments as I would have had spelling errors galore and taken tooooo [sic] long to finish."

Regardless of available support and flexibility, illness, disability, and personal crises sometimes effected participants' capacity to focus effectively on study. Unanticipated illness and personal challenges, such as the death of a loved one or a natural disaster, effected students' physical and psychological wellbeing, and their capacity to focus on studies. Where students were unable to participate fully due to disability, illness, or wellbeing concerns, they fell behind, and felt unable to perform their best. Lucy, for instance, described the influence of mental illness on her first year, adding: "I had applied for a LAP [Learning Access Plan] which gave me extra time in exam ... I am still not well after really stressing over the exam."

Many participants appreciated the capacity to read/listen to lectures wherever comfortable, including in transit, though sometimes struggled to find spaces free of distraction. Where students lacked a dedicated home office, they found it difficult to avoid distractions. Andrea, for instance, desired a more suitable study environment following her first semester, saying: "Am trying to convince the husband to build an office so I can have a space at home to study that I can close the door and focus."

\section{Interaction}

Alongside participants' personal characteristics and situations, participants discussed experiences of their institution. The interaction theme referred to formal or informal opportunities to connect and engage with instructors, peers, and course content. Participants appreciated approachable, understanding, encouraging, and responsive instructors, who provided clear instructions and feedback, and actively participated in discussion forums. However, the extent and quality of instructor interaction varied. Some instructors were felt to have provided highly effective guidance, feedback, and support, while others offered very limited contact, and insufficient advice and feedback. Inconsistencies and poor instructor guidance were especially frustrating. As Brooke described, following her first semester: "No communication with my lecturer ... No feedback, no contact ... It has led to a lot of frustration ... I had no idea whether I was on track or not."

Some units involved regular, compulsory class discussions and group work, while others offered very little peer interaction. Participants appreciated the personal support, experience, and advice offered by peers, facilitating learning and normalising challenges, which reduced anxiety and created a sense of belonging. Compulsory discussions and group work were often time-consuming and frustrating, however, while a lack of peer interaction was experienced as isolating and lonely, leaving many participants feeling disconnected from the university community. Ryan, for instance, expressed disappointment during his first semester, 
describing: "No [peer interaction], which certainly doesn't help and is quite a hinderance [sic] ... Was more isolating than expected."

The manner in which students engaged with course content also varied between units. Where provided, audio-visual learning materials, lecture recordings, audio-narrated slideshows, videos, synchronous chat sessions, and opportunities to explore and discuss content with instructors, made content engaging and easier to digest. Many participants described a large amount of reading being required, nonetheless, with some units relying solely on texts with insufficient explanation, leaving students feeling lost and abandoned. As Brooke described, in her first semester: "The power-points are almost useless as they need the commentary to make sense."

\section{Curriculum}

The curriculum theme referred to course content, design, and configurations, and associated flexibility, challenge, and relevance. Several participants described struggling with particular topics, especially mathematics, finding associated assessment especially difficult. Students were also sometimes personally challenged, forced to consider different perspectives, which threatened prior assumptions. They valued such challenges, nonetheless, and described these as essential to feeling engaged, and for success to be meaningful. However, some participants felt their course lacked sufficient challenge, leaving them bored, disengaged, and questioning the value of their studies. Keven, for instance, described the lack of challenge in his first semester, adding: "Units are designed for school leavers ... to me they are a waste of time ... Not difficult really."

Participants experienced varying degrees of course flexibility, and many were surprised to learn of compulsory, scheduled activities in some units. They appreciated being able to study when and how they wanted, able to minimise distractions, adapt efforts for more difficult/easier activities, and to move ahead during quieter periods. Regular activities helped participants stay on track, however, these also created time management difficulties. As Teresa described, following her first semester: "Offcampus students are offcampus for a reason - we don't have time to attend lects [sic] and tuts [sic]."

Participants largely found the curriculum relevant to their career and employment aspirations, and felt units complemented each other well. After completing only one or two semesters, some had also begun to think about postgraduate study. Layla, for instance, described her first semester having: "[E]xtended my knowledge and provided a more professional approach for me to add to my existing skills."

\section{Environment}

The environment theme referred to the university systems (technology) and processes (online delivery) through which participants accessed and engaged with learning activities. Many participants described their experience as lower quality and more costly than anticipated. They felt disadvantaged as online students, believing OE to require greater concentration, organisation, and self-direction than on-campus education. Many participants felt these additional challenges were insufficiently acknowledged or addressed by the university, leaving them feeling neglected. Marcus, for instance, described feeling the university had not prioritised online students during his first semester, adding: "The impression I got (rightly or wrongly) with [the university] was that the lights were out, and servicing online students was not a high priority."

Technology offered participants convenience, portability of learning materials and flexibility to participate at opportune times. However, many struggled to navigate systems initially, frustrated by layout inconsistencies within the learning management system, which made it difficult to locate important information. Some also felt technology was not well applied or managed by instructors, causing compatibility and access issues. Participants found associated technical difficulties frustrating, effecting access to important information and submission of assignments. As Alana described, following her second semester: "A real nightmare. Blackboard was down so many times ... It was really frustrating!" 


\section{Discussion and recommendations}

This research offers a broad, unrestricted, and systemic perspective of OE. It is the first of its kind to offer a student-centred, holistic depiction of the OSE, which considers the total student experience, consistent with the broader HE sector (Benckendorff et al., 2009). Participants' experiences offer a multifaceted portrayal of the online first-year university student experience, with each identified theme representing an important component from the student perspective. Collectively, learner motivation, ability, and circumstances, combined with institutional interaction, curriculum, and environment, described participants' lived experiences of OE, forming a MAC-ICE thematic structure of the OSE.

The findings highlight complexity in the OSE, reflecting an interplay of student characteristics and circumstances, alongside institutional products and support. Experiences associated with both the learner and their institution appear at the core of students' lived experiences, each playing a notable role. This complexity has implications for both how one researches $\mathrm{OE}$, and how universities might ensure a quality OSE.

The multifaceted, student-centred understanding of the OSE, provided by this research, offers propositions as to why some students may perform more poorly, feel less satisfied, or withdraw in greater numbers from some online courses, revealing valuable opportunities to enhance online student outcomes. Prior research has shown motivational factors to be associated with learning, satisfaction, performance, and retention outcomes (Bawa, 2016; Chen et al., 2017). Student ability has also been linked to learning, academic performance, satisfaction, and retention (Chen et al., 2017; Su \& Waugh, 2018; Terry et al., 2016; Yu \& Richardson, 2015). Students' broader circumstances, such as employment commitments, family responsibilities, and support, have also been associated with academic success, satisfaction, and online student attrition (Creed et al., 2015; Moore \& Greenland, 2017; Palmer et al., 2011). In addition, interaction with instructors, content, and peers has been found to contribute to online students' learning, performance, satisfaction, and retention (Bawa, 2016; Bourdeaux \& Schoenack, 2016; Garratt-Reed et al., 2016; Oh \& Kim, 2016). Curriculum challenge, flexibility, and relevance have been linked to student satisfaction and retention (Bradford, 2011; Su \& Waugh, 2018); and technical difficulties can contribute to students' dissatisfaction and attrition (Bawa, 2016; Ilgaz \& Gulbahar, 2015). With each MAC-ICE theme having potential to influence online student outcomes, this research highlights the importance of considering the total OSE, and the particular challenges described by participants in relation to each theme, when seeking to design or evaluate quality $\mathrm{OE}$.

The findings further suggest a unique context associated with the OSE, reflecting potential differences between on-campus and online student profiles and circumstances, as well as how students may engage with their institution (Wieser et al., 2017). This research provides empirical support for the role of online delivery in a quality student experience (Willging \& Johnson, 2009), highlighting particular components of the OSE perceived to differ to traditional education. Participants described notable challenges in managing technical requirements and competing priorities, in particular, alongside inadequate instruction and infrastructure, signalling additional difficulties assumed not to be experienced by their on-campus peers. Students may therefore perceive OE, to require more work (Huang et al., 2011), greater concentration, better time management (Huang et al., 2011), more self-regulation (Bawa, 2016), and a heavier reliance on technology (Antonis et al., 2011), than on-campus education. In addition, the findings highlight the particular significance of the online first-year transition, with participants describing a potentially overwhelming learning curve as they attempted to navigate online and university learning environments, while managing personal challenges and competing priorities alongside their studies (Nelson, 2008). The first-year transition to HE, therefore, may be more cumbersome for online students, than their on-campus peers.

\section{Implications for OE theory and research}

Participants' experiences show notable consistencies with prior qualitative investigations of OE, indicating strong validity of the findings of this research. Online students in O'Shea et al. (2015) study, for instance, also desired meaningful peer interaction, recognition of their online status, online-focused curriculum design, accessible and responsive instructors, and assistance with technology. Stone et al.'s (2016) investigation of online first-in-family student experiences similarly supports the present research findings, with regard to students' personal motivations to engage in OE and the perceived importance of family and 
employer support, as well as understanding and encouraging instructors. Identified themes, reflect many of Stone's (2017) guidelines for improving access, participation and success in OE, providing strong support for their application. Specifically, appreciating online students' unique needs, establishing and adhering to OE quality standards, supporting students to develop their skills, and explicitly prioritising online instruction and delivery at an institutional level, may be highly valued by online students.

This research offers a much needed student-centred and holistic perspective to supplement and clarify understanding of the OSE. The multifaceted nature of participants' lived experiences has implications for how OE is understood and researched. Prior studies may have been confounded, for instance, where particular MAC-ICE themes have not been considered. The lack of comprehensive descriptions in existing literature makes it difficult to determine all conditions experienced by research participants, and, therefore, to verify all themes have been addressed. Though Garratt-Reed et al. (2016) made every effort to facilitate equivalent academic conditions in comparing online and face-to-face student outcomes, for instance, potential differences in student characteristics and circumstances were not reported. It is conceivable that circumstantial differences between the two cohorts could have contributed to online students' comparatively poor performance, particularly in relation to their group assignment (Delahunty et al., 2014). OE research may be more meaningful, therefore, where associated methodology and findings consider and clarify the status of all MAC-ICE themes, enabling readers to consider the contribution of particular OSE components, and to evaluate reliability of associated findings.

Participants' descriptions suggest there may be important perceived differences between the on-campus and OSE, which challenge the validity of on-campus/OE comparisons. Where such differences are not actively considered, comparative studies may be confounded by one group experiencing potentially different conditions. Further research is needed to better understand these perceived differences, and to generate genuinely equivalent experiences of on-campus and $\mathrm{OE}$.

The findings suggest a holistic understanding of the OSE is essential to appreciate the wide range of experiences which may contribute to quality $\mathrm{OE}$, in line with the notion of the total student experience (Benckendorff et al., 2009). Clear empirical support is offered for broad conceptualisation of the OSE, considering the full lived experience of online students, incorporating institutional and learner factors, and taking account of particular conditions associated with online delivery. The total OSE must be considered when investigating $\mathrm{OE}$ to ensure critical factors are not overlooked. The circumstances in which students engage with $\mathrm{OE}$, in particular, provide an important lens through which the OSE should be interpreted (Wieser et al., 2017), especially in the context of COVID-19. The MAC-ICE themes described in the present research, suggest important aspects of the OSE to be further investigated if universities are to ensure quality $\mathrm{OE}$ and associated student outcomes.

\section{Implications for OE policy and practice}

This research offers opportunities to enhance policy and practice, through appreciation for the range of experiences contributing to the OSE, in the eyes of students. Both learners and their institution play a role in the OSE. Online students' motivation, ability, and circumstances may inform their lived experiences of OE. Universities may play a role, nonetheless, in encouraging, inspiring, and supporting students to strengthen their motivation and ability, and to establish circumstances conducive to a quality OSE, while ensuring quality interaction, curricula, and learning environments.

Universities should actively consider learner themes in promoting OE and providing student support. Considering students' concentration, commitment, interests, and self-efficacy, and emphasising rewards, when promoting and delivering $\mathrm{OE}$, for instance, may reinforce students' motivation and persistence (Ciampa, 2014). Identified learner characteristics may offer potential selection criteria and opportunities for meaningful course advice (Chen et al., 2017), helping to place students into appropriate pathways (Money et al., 2017). Conveying the importance of learner themes, alerting commencing students to requisite skillsets and time commitments, and connecting these to available preparatory programs and support services, may further empower students to assess their capacity, proactively develop requisite skills and manage peripheral circumstances ( $\mathrm{Su} \&$ Waugh, 2018). Challenges faced by some participants highlight the value of accessible online student support, which may facilitate a more equitable learning curve and manageable first-year transition (Stone \& O'Shea, 2019). Raising awareness of such support, normalising and encouraging online students to access services, may further assist students to address 
challenges (Stone \& O'Shea, 2019). This support may be crucial in the context of COVID-19, which has created additional challenges, with regard to financial, health, and family circumstances (Drane et al., 2020).

Institutional themes may be especially relevant to university policy and practice. Participants' experiences offer valuable propositions for quality OE applicable to university standards and quality assurance mechanisms in regard to interaction, curricula, and learning environments. Meaningful interaction with peers and instructors, dynamic and engaging learning activities, and the application of innovative technology should be actively encouraged (Stone, 2017; Tomas et al., 2015). Instructors who are accessible and responsive (Stone \& O'Shea, 2019), facilitation of opportunities for meaningful peer interaction (Oh \& Kim, 2016), use of a variety of dynamic materials and strategies to engage students (Bourdeaux \& Schoenack, 2016), and encouraging the application of learning beyond the course (Sansone et al., 2012), may facilitate a more positive OSE.

Curricula should also be challenging, clearly relevant, and offer some flexibility (Mason et al., 2015), while associated technology should be accessible and reliable (Ilgaz \& Gulbahar, 2015). Online course design should consider students' circumstances, with alternatives available where students cannot participate in synchronous learning activities (Stone \& O'Shea, 2019). Standards of assessment and support should be commensurate with those provided to on-campus students, or else differences explained and mitigated (Tomas et al., 2015). Reliable and innovative applications of technology may be essential for online students to access and participate in their studies (Tomas et al., 2015). The application of technology, nonetheless, is limited by instructors' capability to use it, and faculty must ensure their own capabilities to facilitate quality OE (Bawa, 2016). With the line between on-campus and OE continuing to blur (Norton et al., 2013), these strategies may enable universities to consider how they use technology in all modes of delivery.

The diversity of participants' experiences suggests there may be no standard model of OE, even within the same institution. This diversity has implications for conceptualising OE quality. In particular, inconsistencies between the flexibility and level of interaction offered in some units, and in how OE is promoted, may cause substantial frustration and difficulties for students (Moore \& Greenland, 2017). The establishment of a standard structure for online units, or else a means of clearly articulating the degree of flexibility and interaction within units, prior to enrolment, may empower students to anticipate and manage their study requirements. Institutional guidelines, nonetheless, may be insufficient to ensure consistent standards, given participants voiced substantial disappointment with the quality of instruction, peer interaction, and online conditions experienced, despite university guidelines supporting good practice. Employing active quality assurance mechanisms, therefore, is equally important to facilitate a quality OSE (Stone, 2017).

This research clarifies the important and broad role for universities in facilitating a quality OSE. University administrators should set clear standards and ensure accountability for adhering to best-practice online course design and delivery (Stone, 2017). Unit and course coordinators should consider all MAC-ICE themes, especially the flexibility, challenge, and relevance offered by their curriculum, in developing online programs, with support from learning designers and technical staff to facilitate an engaging and reliable learning environment (Stone, 2017). Instructors may further enhance the OSE through regular guidance, feedback, and support (Bourdeaux \& Schoenack, 2016), and encouraging students to interact in meaningful ways (O'Shea et al., 2015). In addition, university advisors and support services should provide clear information on what $\mathrm{OE}$ entails, promote and normalise online student support, and facilitate equivalent opportunities for students who cannot attend campus (Su \& Waugh, 2018).

\section{Limitations and future work}

This research is limited to the experiences of a group of students at one university. The findings cannot be generalised, but propose explanations that may be transferable to similar contexts. Replication of the research methodology at other institutions, would enable validation of these findings for other online firstyear student populations. A larger, quantitative study is also needed to assess the prevalence of identified experiences, and to understand their effects on corresponding outcomes. The widespread move to OE associated with COVID-19, warrants further investigation to ascertain the impact of this increased focus on online delivery, amidst challenging circumstances. In addition, consideration of all identified themes in 
OE research would enhance investigation, understanding, and interpretation of the OSE; and illuminate any variance explained by confounding factors in prior studies.

In addition to validating the findings for the broader population, further research would be valuable to uncover additional perspectives of OE. In particular, it is important to understand the lived experience of online instructors. International students also represent an important market for OE, and it would be useful to know how their experiences might differ from domestic online students. The development described by participants across their first year, suggest some challenges may diminish as students advance beyond their first year. Replicating the present research with instructors, international students, and later-year undergraduate/postgraduate online students, would offer important information to supplement the findings.

\section{Conclusion}

This research offers rich descriptions of students' lived experiences of their first year in OE. The OSE may be informed by students' own motivation, ability, and circumstances, alongside the interaction, curriculum, and environment facilitated by their institution. Where online students are deeply motivated, possess the necessary skills to participate effectively, and are situated in conducive circumstances, they may be well placed for a positive OSE. Supplementing this, universities may facilitate a quality OSE through: (a) meaningful interaction with instructors, peers, and course content; (b) flexible, relevant and challenging curricula; and (c) delivering $\mathrm{OE}$ within a reliable and innovative learning environment that offers a commensurate experience to on-campus education.

This research suggests opportunities to enhance the OSE through consideration of learner and institutional themes. It contributes new knowledge to the field of OE, providing a comprehensive, student focused description of the OSE, which until now has been fragmented and incomplete. The findings suggest opportunities for prior research to be further scrutinised, and the OSE thoroughly examined, enabling researchers, policy-makers, and universities to identify, investigate, and implement strategies to attract and retain online students.

\section{References}

Allen, I. E., \& Seaman, J. (2014). Grade change: Tracking online education in the United States. http://www.onlinelearningsurvey.com/reports/gradechange.pdf

Antonis, K., Daradoumis, T., Papadakis, S., \& Simos, C. (2011). Evaluation of the effectiveness of a webbased learning design for adult computer science courses. IEEE Transactions on Education, 54(3), 374-380. https://doi.org/10.1109/te.2010.2060263

Bawa, P. (2016). Retention in online courses: Exploring issues and solutions - A literature review. SAGE Open, 6(1), 1-11. https://doi.org/10.1177/2158244015621777

Benckendorff, P., Ruhanen, L., \& Scott, N. (2009). Deconstructing the student experience: A conceptual framework. Journal of Hospitality and Tourism Management, 16(1), 84-93. https://doi.org/10.1375/jhtm.16.1.84

Borrello, E. (2020). WA universities suffer huge coronavirus income losses as international students stay away. https://www.abc.net.au/news/2020-05-27/uwa-curtin-big-covid-losses-as-internationalstudents-stay-away/12291722

Bourdeaux, R., \& Schoenack, L. (2016). Adult student expectations and experiences in an online learning environment. The Journal of Continuing Higher Education, 64(3), 152-161. https://doi.org/10.1080/07377363.2016.1229072

Bradford, G. R. (2011). A relationship study of student satisfaction with learning online and cognitive load: Initial results. Internet and Higher Education, 14(4), 217-226. https://doi.org/10.1016/j.iheduc.2011.05.001

Braun, V., \& Clarke, V. (2006). Using thematic analysis in psychology. Qualitative Research in Psychology, 3(2), 77-101. https://doi.org/10.1191/1478088706qp063oa

Cavanaugh, J. K., \& Jacquemin, S. J. (2015). A large scale comparison of grade based student learning outcomes in online vs. face-to-face courses. Journal of Asynchronous Learning Networks, 19(2). https://doi.org/10.24059/olj.v19i2.454

Chamberlain, B. (2009). Phenomenology: A qualitative method. Clinical Nurse Specialist, 23(2), 52-53. https://doi.org/10.1097/nur.0b013e3181996ae5 
Chen, C., Jones, K. T., \& Moreland, K. (2017). How online learning compares to the traditional classroom: measuring accounting course outcomes. The CPA Journal, 87(9), 44-50.

Chrysanthos, N. (2020, June 7). Students fear lost semester of learning as universities plan for campus return. The Sydney Morning Herald. https://www.smh.com.au/national/nsw/students-fear-lostsemester-of-learning-as-universities-plan-for-campus-return-20200605-p54zw5.html

Ciampa, K. (2014). Learning in a mobile age: An investigation of student motivation. Journal of Computer Assisted Learning, 30(1), 82-96. https://doi.org/10.1111/jcal.12036

Creed, P. A., French, J., \& Hood, M. (2015). Working while studying at university: The relationship between work benefits and demands and engagement and well-being. Journal of Vocational Behavior, 86, 48-57. https://doi.org/10.1016/j.jvb.2014.11.002

Delahunty, J., Verenikina, I., \& Jones, P. (2014). Socio-emotional connections: Identity, belonging and learning in online interactions. A literature review. Technology, Pedagogy and Education, 23(2), $243-$ 265. https://doi.org/10.1080/1475939X.2013.813405

Drane, C., Vernon, L., \& O'Shea, S. (2020). The impact of 'learning at home' on the educational outcomes of vulnerable children in Australia during the COVID-19 pandemic. National Centre for Student Equity in Higher Education, Curtin University. https://www.ncsehe.edu.au/wpcontent/uploads/2020/04/NCSEHE_V2_Final_literaturereview-learningathome-covid19final_30042020.pdf

Driscoll, A., Jicha, K., Hunt, A. N., Tichavsky, L., \& Thompson, G. (2012). Can online courses deliver in-class results? A comparison of student performance and satisfaction in an online versus a face-toface introductory sociology course. Teaching Sociology, 40(4), 312-331. https://doi.org/10.1177/0092055X12446624

Findlay, L., Ballinger, C., \& Hoboken, N. (Eds.) (2006). Qualitative research for allied health professionals: Challenging choices. J Wiley \& Sons.

Garratt-Reed, D., Roberts, L. D., \& Heritage, B. (2016). Grades, student satisfaction and retention in online and face-to-race introductory psychology units: A test of equivalency theory. Frontiers in Psychology, 7(Article 673), 1-10. https://doi.org/10.3389/fpsyg.2016.00673

Guba, E. G., \& Lincoln, Y. S. (1982). Epistemological and methodological bases of naturalistic inquiry. Educational Communication and Technology, 30(4), 233-252.

Huang, X., Dedegikas, C., \& Walls, J. (2011). Using multimedia technology to teach Modern Greek language online in China: Development, implementation and evaluation. European Journal of Open, Distance and E-Learning, 1, 1-9.

Ilgaz, H., \& Gulbahar, Y. (2015). A snapshot of online learners: e-Readiness, e-ratisfaction and expectations. International Review of Research in Open and Distributed Learning, 16(2), 171-187. https://doi.org/10.19173/irrodl.v16i2.2117

Karlsson, C. (1993). Psychological qualitative research from a phenomenological perspective. Almqvist \& Wiksell International.

Kleiman, S. (2004). Phenomenology: To wonder and search for meanings. Nurse Researcher, 11(4), 7-19. https://doi.org/10.7748/nr2004.07.11.4.7.c6211

Lo, C. C., Johnson, E., \& Tenorio, K. (2011). Promoting student learning by having college students participate in an online environment. Journal of the Scholarship of Teaching and Learning, 11(2), 115.

Mason, D., Barnes, C., \& Shelton, K. (2015, October 14-16). Experiences of successful undergraduate students in online science courses [Paper presentation]. 21st Annual Online Learning Consortium International Conference 2015, Orlando, FL.

Money, J., Nixon, S., Tracy, F., Hennessy, C., Ball, E., \& Dinning, T. (2017). Undergraduate student expectations of university in the United Kingdom: What really matters to them? Cogent Education, 4(1), 1-11. https://doi.org/10.1080/2331186X.2017.1301855

Moore, C., \& Greenland, S. (2017). Employment-driven online student attrition and the assessment policy divide: an Australian open-access higher education perspective. Journal of Open, Flexible and Distance Learning, 21(1), 52-62.

Nelson, J. A. (2008). Advantages of online education. Home Health Care Management and Practice, 20(6), 501-502. https://doi.org/10.1177/1084822308319681

Norton, A., Sonnemann, J., \& McGannon, C. (2013). The online evolution: When technology meets tradition in higher education. https://grattan.edu.au/report/the-online-evolution-when-technologymeets-tradition-in-higher-education/

O'Shea, S., Stone, C., \& Delahunty, J. (2015). "I 'feel' like I am at university even though I am online." Exploring how students narrate their engagement with higher education institutions in an online 
learning environment. Distance Education, 36(1), 41-58.

https://doi.org/10.1080/01587919.2015.1019970

Oh, E. G., \& Kim, H. S. (2016). Understanding cognitive engagement in online discussion: Use of a scaffolded, audio-based argumentation activity. International Review of Research in Open and Distributed Learning, 17(5), 28-48. https://doi.org/10.19173/irrodl.v17i5.2456

Palmer, R. T., Davis, R. J., \& Maramba, D. C. (2011). The impact of family support on the success of black men at an historically black university: Affirming the revision of Tinto's theory. Journal of College Student Development, 52(5), 577-597. https://doi.org/10.1353/csd.2011.0066

Quality Indicators for Learning and Teaching (2020). Student experience. https://www.qilt.edu.au/qiltsurveys/student-experience

Sansone, C., Smith, J., Thoman, D., \& MacNamara, A. (2012). Regulating interest when learning online: Potential motivation and performacne trade-offs. Internet and Higher Education, 15(3), 141-149. https://doi.org/10.1016/j.iheduc.2011.10.004

Stone, C. (2017). Opportunity through online learning: Improving student access, participation and success in higher education. National Centre for Student Equity in Higher Education, Curtin University.

Stone, C., \& O'Shea, S. (2019). My children ... think it's cool that Mum is a uni student: Women with caring responsibilities studying online. Australasian Journal of Educational Technology, 35(6), 97110. https://doi.org/10.14742/ajet.5504

Stone, C., O'Shea, S., May, J., Delahunty, J., \& Partington, Z. (2016). Opportunity through online learning: Experiences of first-in-family students in online open-entry higher education. Australian Journal of Adult Learning, 56(2), 146-169. https://files.eric.ed.gov/fulltext/EJ1107574.pdf

$\mathrm{Su}$, J., \& Waugh, M. L. (2018). Online student persistence or attrition: Observations related to expectations, preferences, and outcomes. Journal of Interactive Online Learning, 16(1), 63-79. http://www.ncolr.org/jiol/issues/pdf/16.1.4.pdf

Terry, N. B., de La Harpe, K., \& Kontur, F. J. (2016). The development of a learning gap between students with strong prerequisite skills and students with weak prerequisite skills. Journal of College Science Teaching, 45(3). https://doi.org/10.2505/4/jcst16_045_03_34

Tomas, L., Lasen, M., Field, E., \& Skamp, K. (2015). Promoting online students' engagement and learning in science and sustainability preservice teacher education. Australian Journal of Teacher Education, 40(11), 79-107. https://doi.org/10.14221/ajte.2015v40n11.5

Wieser, D., Seeler, J. M., Sixl-Daniell, K., \& Zehrer, A. (2017, June). Online students' expectations differ: The advantage of assessing students' expectations in online education. Proceedings of the 3rd International Conference on Higher Education Advances, HEAd'17, Univerrsitat Politecnica de Valencia, Valencia. https://doi.org/10.4995/head17.2017.5525

Willging, P. A., \& Johnson, S. D. (2009). Factors that influence students' decision to dropout of online courses. Journal of Asynchronous Learning Networks, 13(3), 115-127.

Wynegar, R. G., \& Fenster, M. J. (2009). Evaluation of alternative delivery systems on academic performance in college algebra. College Student Journal, 43(1), 170-174.

Xu, D., \& Jaggars, S. S. (2014). Performance Gaps Between Online and Face-to-Face Courses: Differences Across Types of Students and Academic Subject Areas. The Journal of Higher Education, 85(5), 633-659. https://doi.org/10.1353/jhe.2014.0028

Yu, T., \& Richardson, J. C. (2015). An exploratory factor analysis and reliability analysis of the student online learning readiness (SOLR) instrument. Online Learning, 19(5), 120-141. https://doi.org/10.24059/olj.v19i5.593

Corresponding author: Mel Henry, mel.henry@curtin.edu.au

Copyright: Articles published in the Australasian Journal of Educational Technology (AJET) are available under Creative Commons Attribution Non-Commercial No Derivatives Licence (CC BY-NCND 4.0). Authors retain copyright in their work and grant AJET right of first publication under CC BYNC-ND 4.0.

Please cite as: Henry, M. (2021). The online student experience: A MAC-ICE thematic structure. Australasian Journal of Educational Technology, 37(4), 159-172. https://doi.org/10.14742/ajet.6619 